Research Article

\title{
Chloride Penetration into Concrete under the Coupling Effects of Internal and External Relative Humidity
}

\author{
Fangzhi Zhu, ${ }^{1,2}$ Zhiming Ma ${ }^{D},{ }^{3}$ and Mingmin Zhang ${ }^{2}$ \\ ${ }^{1}$ School of Civil Engineering and Architecture, Suqian College, Suqian 223800, China \\ ${ }^{2}$ College of Civil Engineering, Qingdao University of Technology, Qingdao 266033, China \\ ${ }^{3}$ College of Civil Science and Engineering, Yangzhou University, Yangzhou 225127, China \\ Correspondence should be addressed to Zhiming Ma; 10351163mzm@tongji.edu.cn
}

Received 1 August 2019; Revised 18 December 2019; Accepted 31 December 2019; Published 11 February 2020

Academic Editor: Claudio Mazzotti

Copyright ( $\odot 2020$ Fangzhi Zhu et al. This is an open access article distributed under the Creative Commons Attribution License, which permits unrestricted use, distribution, and reproduction in any medium, provided the original work is properly cited.

Chloride penetration frequently happens in an unsaturated concrete; in this case, the chloride migration is under the coupling effects of internal moisture and external relative humidity (RH). Various chloride attack tests were designed in this paper to investigate the effects of internal moisture and external $\mathrm{RH}(50-100 \%)$ on the chloride penetration into an unsaturated concrete, and the chloride content was determined to quantify the chloride migration in concrete. The results highlighted that there was a good correlation between the chloride penetration into concrete and its internal RH. The chloride ion was difficult to penetrate into concrete when its internal $\mathrm{RH}$ was below $50 \%$; however, the chloride penetration rate increased when the internal $\mathrm{RH}$ of concrete was above $75 \%$, and the chloride migration increased with increasing $\mathrm{RH}$ and exposure duration. Water evaporation in concrete increased with decreasing external $\mathrm{RH}$, and an obvious increase in the surface chloride content may be observed when external RH was 50\%; however, when external $\mathrm{RH}$ was above $75 \%$, the inner chloride content increased and surface chloride content decreased with increasing exposure duration. Simulating the chloride penetration under wet-dry cycling, the water migration resulted in an increase in the surface chloride content and a decrease in the inner chloride content, and the chloride crystal precipitated on the surface of concrete with a high w/c ratio.

\section{Introduction}

With rapid development of construction technology, concrete structure was inevitably exposed to various harsh environments, mainly including chloride attack, freezingthawing, and carbonation environments [1-3]. In particular, chloride penetration frequently resulted in the steel corrosion of reinforced concrete and reduced its service life, which was a key indicator for concrete durability $[4,5]$. Worldwide scholars have conducted a mass of studies to investigate the chloride penetration into concrete, and they found that the chloride penetration was different when concrete subjected to various exposure environments; moreover, the capillary absorption, concentration gradient, and convection provided the main driving force for chloride penetration into concrete [6-8]. In any case, the chloride migration was controlled by the internal moisture content of concrete and the external $\mathrm{RH}$ of the exposure environment.

For concrete subjected to underwater, the chloride penetration into saturated concrete has been systematically investigated by scholars around the world, and some valuable conclusions have been obtained $[9,10]$. For simulating the chloride migration in an unsaturated concrete when exposed to marine tidal zone and spray zone, the chloride penetration was frequently determined by capillary absorption test and wet-dry cycling test, and the previous study reported that the chloride penetration was close to the wet-dry cycles, ion concentration and exposure duration [11-13]. However, a quantitative test to evaluate the chloride migration in such unsaturated concrete was lacking, and the influence mechanism of water convection on the chloride migration was not clear yet. 
In practice, the concrete with various moisture content was frequently subjected to the condition with various $\mathrm{RH}$ values, and the previous investigations found that the internal moisture content and external $\mathrm{RH}$ have an obvious impact on the properties of concrete. For the mechanical properties, Barluenga et al. [14] and Han et al. [15] investigated the impact of applied curing $\mathrm{RH}$ on the mechanical properties of concrete, and the results reported that increasing curing $\mathrm{RH}$ was helpful to the strength of concrete. For the early age and long-time deformation of concrete, Yalçınkaya and Yazıcı [16] and Frech-Baronet et al. [17] studied the effect of RH on the shrinkage and creep of concrete, and the results reported that the shrinkage value decreased with increasing $\mathrm{RH}$, whereas the increasing $\mathrm{RH}$ led to a decrease in the indentation modulus and long-term creep rate was increased. For the durability of concrete, the previous investigations found that the carbonation rate of concrete exposed to $40-70 \% \mathrm{RH}$ was higher than that exposed to other RH [18-20]. Some scholars further investigated the influence of $\mathrm{RH}$ and moisture content on the chloride penetration into concrete; for example, Homan et al. [21] reported that the increasing internal moisture content aggravated the chloride penetration, and the water convection had a significant impact on chloride migration in concrete [22]. Bastidas-Arteaga et al. [23] and Samson et al. [24] proposed a comprehensive probabilistic model to predict the chloride migration in an unsaturated concrete, and the influence factors of moisture content and RH were considered in this model. However, a quantitative test for determining the influence of internal moisture and external $\mathrm{RH}$ on the chloride penetration was lacking, which was helpful to better understand the chloride migration in an unsaturated concrete.

Based on the introduction above, this paper was developed to investigate the effects of internal moisture content and external $\mathrm{RH}$ on chloride penetration into concrete. The concrete specimen with various sizes was first prepared, and then various chloride attack tests were designed and applied on the specimen with various internal moisture content and external RH values (50-100\%). The chloride content was determined to quantify the chloride distribution in concrete under the coupling effect of internal and external $\mathrm{RH}$; moreover, the chloride penetration with coupling effects of water convection was also determined in this paper, which was helpful to achieve a better understanding on the chloride penetration into concrete under wet-dry cycling. We hope the findings in this paper were helpful to the further investigation of chloride penetration into unsaturated concrete.

\section{Materials and Experimental Details}

2.1. Mixture Proportions and Concrete Specimens. Table 1 shows the mix proportion of concrete. The grade of Portland cement was PO 42.5. The size of the natural coarse aggregate was $5-25 \mathrm{~mm}$, and the fineness module of sand was 2.9. The water-to-cement ratio (w/c) of concrete in this paper was 0.4 , 0.5 , and 0.6 . To reduce the effect of mixture flowability on the properties of hardened concrete, the slump of all the concrete mixtures with various $\mathrm{w} / \mathrm{c}$ ratios was controlled around $90 \mathrm{~mm}$ by adjusting the content of water reducing agent in such mixture. The cube specimen with the size of $100 \mathrm{~mm}$
TABLE 1: Mix proportion of plain concrete $\left(\mathrm{kg} / \mathrm{m}^{3}\right)$.

\begin{tabular}{lcccc}
\hline Specimens & Cement & Sand & Natural aggregate & Water \\
\hline $\mathrm{w} / \mathrm{c}=0.4$ & 380 & 627 & 1269 & 152 \\
$\mathrm{w} / \mathrm{c}=0.5$ & 320 & 653 & 1267 & 160 \\
$\mathrm{w} / \mathrm{c}=0.6$ & 300 & 699 & 1191 & 180 \\
\hline
\end{tabular}

was first prepared according to the mix proportion in $\mathrm{Ta}$ ble 1 , and the specimens after hardening were placed in a standard curing room for $28 \mathrm{~d}\left(T=20 \pm 2^{\circ} \mathrm{C}, \mathrm{RH} \geq 95 \%\right)$.

\subsection{Experiment for Chloride Penetration into Concrete with} Various Internal Moisture Content. Attributed to that the chloride migration was difficult to happen in concrete when its internal $\mathrm{RH}$ was below $50 \%$, the targeted $\mathrm{RH}$ in this paper was $50-100 \%$. One was expected that the $\mathrm{RH}$ around $80 \%$ may have an obvious impact on the chloride migration in concrete; thus, two similar $\mathrm{RH}$ values (75\% RH and $80 \%$ $\mathrm{RH})$ were presented, and they were also helpful to the testing accuracy in this paper. Figure 1 shows the experimental flow for chloride penetration into concrete with various internal $\mathrm{RH}$ values and the concrete w/c used in this section was 0.5 . Referring to the related references and standard [25, 26], 5\% $\mathrm{NaCl}$ solution was used in the chloride penetration test. Observing from Figure 1(a) when the internal RH of concrete was $50-80 \%$, the cube specimen was first placed into a small specimen with the size of $100 \mathrm{~mm} \times 100 \mathrm{~mm} \times 25 \mathrm{~mm}$, to rapidly reach the targeted internal RH in concrete; and then the specimens were, respectively, placed in a vacuum saturation meter which contained $5 \% \mathrm{NaCl}$ solution and water, and the duration of vacuum filling water was $24 \mathrm{~h}$; in this case, some specimens titled A were saturated with $5 \% \mathrm{NaCl}$ solution, and the other specimens titled B were saturated with water. After that, the specimens were placed in a room with constant temperature and $\mathrm{RH}$ for 2 months, and the targeted internal $\mathrm{RH}$ in the specimen reached $50 \%, 75 \%$, and $80 \%$, respectively. Finally, A specimen and B specimen with the same internal RH were connected with an ultrathin filter paper for 1, 6, and 12 months, and in this case, the chloride ion in A specimen could migrate from $\mathrm{A}$ specimen to $\mathrm{B}$ specimen under the driving force of concentration gradient.

Figure 1(b) shows the experimental flow for chloride penetration into concrete with an internal $\mathrm{RH}$ of $100 \%$, and the specimen size in this test was $100 \mathrm{~mm} \times 100 \mathrm{~mm} \times 50 \mathrm{~mm}$. The specimens were first saturated with $5 \% \mathrm{NaCl}$ solution and water, and in this case, the internal $\mathrm{RH}$ was $100 \%$. Subsequently, the A specimen saturated with $5 \% \mathrm{NaCl}$ solution and $\mathrm{B}$ specimen saturated with water were immediately connected through an ultrathin filter paper, and the connecting duration (chloride penetration time) was 1, 6, and 12 months. After the chloride penetration test, the chloride content in concrete was determined, and the chloride migration under the application of various internal $\mathrm{RH}$ values could be quantified.

2.3. Experiment for Chloride Penetration into Concrete Exposed to Various External RH Values. In this section, the chloride penetration into concrete was studied when 


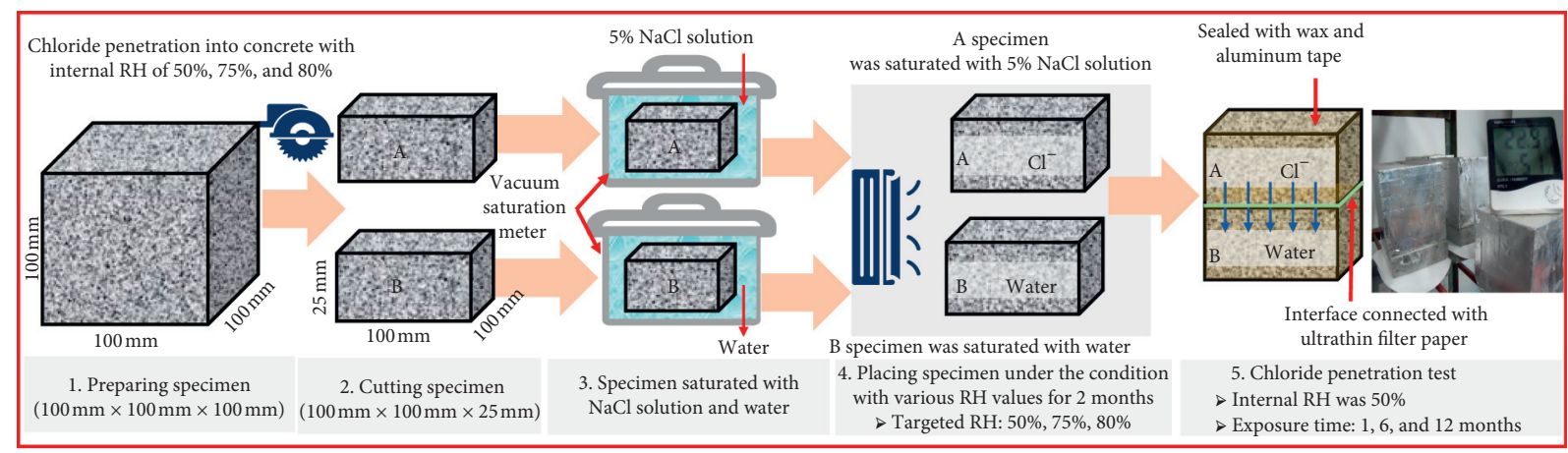

(a)

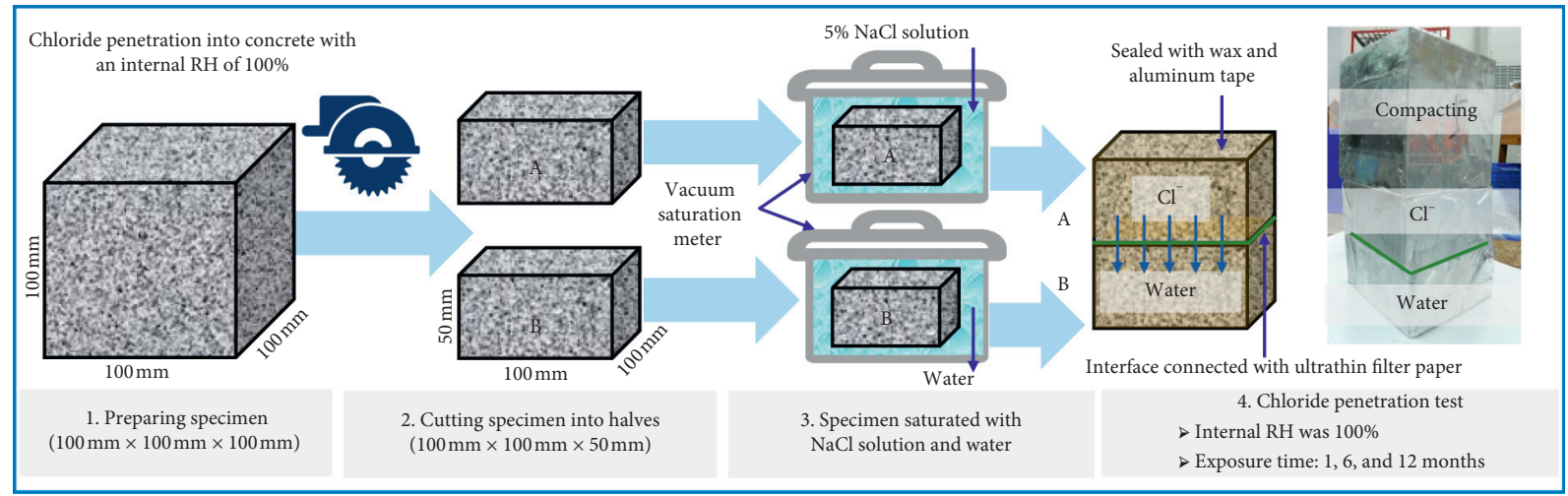

(b)

Figure 1: Experiment flow for the chloride migration into concrete with various internal RH values. (a) When internal RH of concrete was $50 \%, 75 \%$, and $80 \%$. (b) When internal RH of concrete was $100 \%$.

subjected to the external environment with various $\mathrm{RH}$ values. Figure 2 shows the detailed experiment flow. The w/ $\mathrm{c}$ of concrete used in this section was 0.5 , and the specimen size was $100 \mathrm{~mm} \times 100 \mathrm{~mm} \times 100 \mathrm{~mm}$. The specimen after curing was first placed in an air-drying oven until a constant weight was reached. After that, except for the two opposite sides, four sides of the specimen were sealed with wax and aluminum tape. The remaining one side was connected with $5 \% \mathrm{NaCl}$ solution, and the opposite side was exposed to air; in this case, enough chloride penetrated into concrete by capillary absorption, and the whole duration of chloride attack was 1 week. Finally, the specimen after chloride attack was placed in a condition with constant temperature and humidity $\left(T=20^{\circ} \mathrm{C} ; \mathrm{RH}=50 \%, 75 \%\right.$, $80 \%$, and $100 \%$ ), and the chloride penetration into concrete was with the coupling effect of external RH. After 1, 6, and 12 months, the chloride content in such specimen was determined to quantify the chloride distribution in concrete when subjected to various external $\mathrm{RH}$ values.

\subsection{Test for Chloride Migration with the Coupling of Water} Convection. Although numerous studies on the chloride penetration under wet-dry cycling have been conducted, the investigation on the quantitative influence of water convection on the chloride migration in unsaturated concrete was lacking. Simulating the chloride migration under wet-dry cycling, this section investigated the chloride penetration into concrete with the coupling effect of water convection, and meanwhile, the experiment of chloride migration by concentration gradient was further compared. In addition, this test further investigated the effect of chloride attack duration and water convection duration on the chloride distribution in concrete. Figure 3 shows the specific experiment flow. The w/c of concrete used in this section was 0.4 and 0.6 , and the specimen size was $100 \mathrm{~mm} \times 50 \mathrm{~mm} \times 20 \mathrm{~mm}$. The chloride penetration test was first conducted, and the chloride attack duration was 2 and 16 weeks. After an initial chloride attack test, all the surfaces of the part of the speciments were sealed and placed for various durations; in this case, the internal moisture content was $100 \%$, and the chloride migration from a high concentration to a low concentration by the driving force of concentration gradient. The other part of the specimens, after an initial chloride attack test, were subjected to the application of water convection; in the test of chloride-water convection, the chloride attack surface was exposed to the air, and its opposite surface was contacted with water, and the contacting time was $2,4,8$, and 16 weeks. Finally, the chloride content in concrete was determined, which could well quantify the effects of the concentration gradient and convection on chloride migration in concrete.

2.5. Chloride Content Determination. Referring to the related references and Chinese standard Technical specification for 


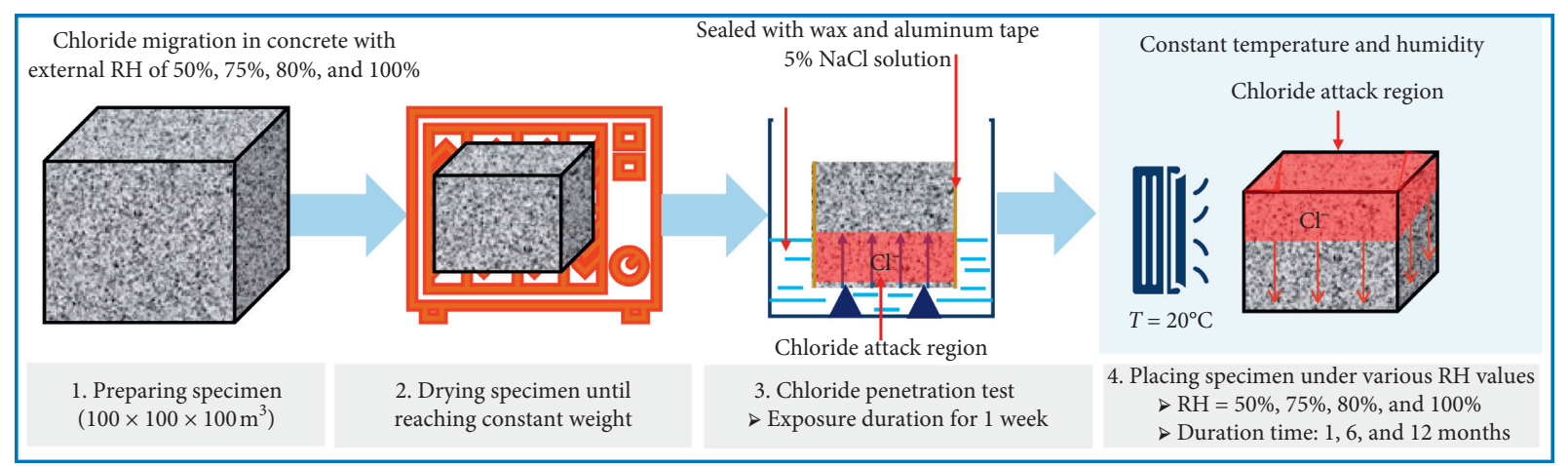

FIGURE 2: Experiment flow for chloride penetration into concrete exposed to various external RH values.

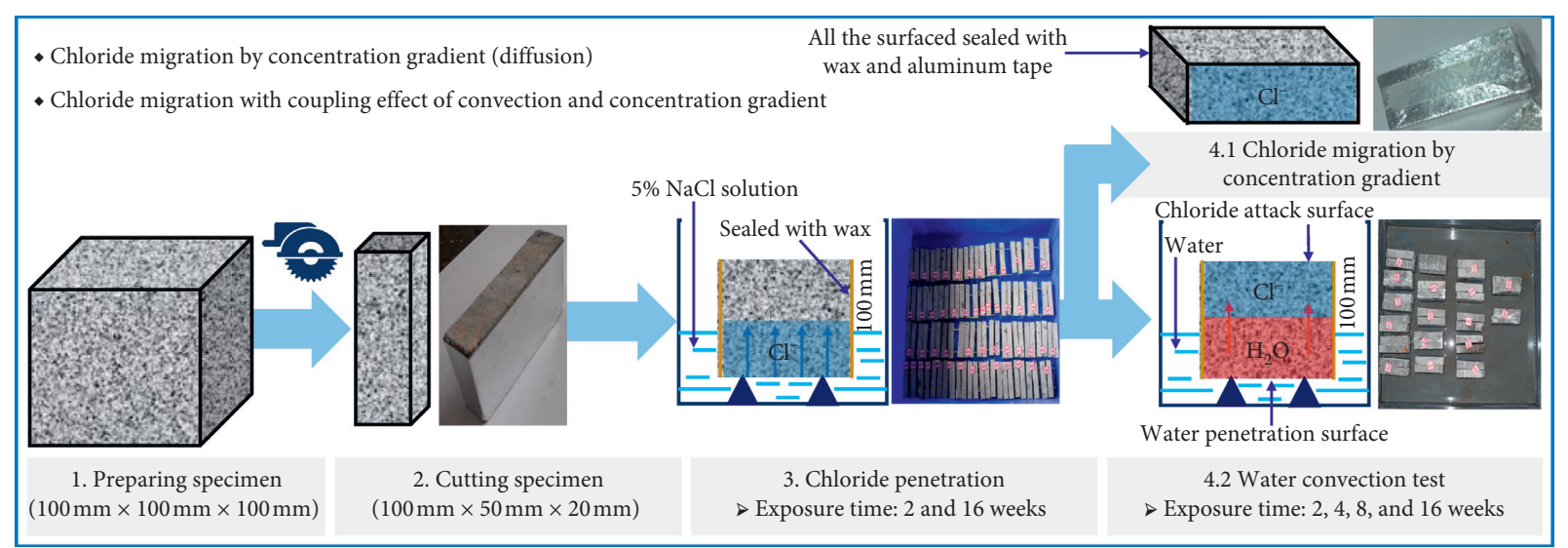

Figure 3: Experiment flow for chloride penetration with coupling of water convection.

test of chloride ion content in concrete (JGJ/T322-2013), the free chloride content was determined by the method of chemical titration [27-29]. Specimens after chloride attack test were dried completely in an air-drying oven until reaching a constant weight $\left(50^{\circ} \mathrm{C}\right.$, approximately $\left.7 \mathrm{~d}\right)$. Subsequently, one layer of the specimen with a thickness of about $1 \mathrm{~mm}$ was milled starting from the chloride attack surface, and the concrete powder derived from various layers was obtained in this way. Finally, the obtained powder was dissolved in water for $24 \mathrm{~h}$; in this case, the free chloride ion contained in powder could be dissolved in water, and finally the chloride content was determined. Equation (1) shows the specific formula used in determining free chloride ion by the method of chemical titration, where $P$ presents the content of free chloride ion, in \%; $\mathrm{C}_{\mathrm{AgNO}_{3}}$ is the concentration of $\mathrm{AgNO}_{3}$ solution, in $\mathrm{mol} / \mathrm{l} ; \mathrm{G}$ presents the weight of concrete powder, in $g ; V_{3}$ stands for the volume of water, in $\mathrm{ml} ; V_{4}$ is the volume of filter liquor, in $\mathrm{ml}$; and $V_{5}$ is the consumed volume of $\mathrm{AgNO}_{3}$ solution, in $\mathrm{ml}$ :

$$
P=\frac{C_{\mathrm{AgNO}_{3}} V_{5} \times 0.03545}{G \times\left(V_{4} / V_{3}\right)} \times 100 \% \text {. }
$$

\section{Experimental Results and Discussion}

3.1. Chloride Penetration into Concrete with Various Internal Moisture Content. Figure 4 shows the chloride content curves of concrete with various internal $\mathrm{RH}$ values, and the surface and maximum chloride content was used to quantify the chloride penetration rate $[30,31]$. When the internal $\mathrm{RH}$ was $50 \%$ and up to 6 months, there was no obvious decrease in the chloride content in the A specimen that was saturated with $\mathrm{NaCl}$ solution, and there was a slight increase in the chloride content in the B specimen that was saturated with water. When the exposure duration was 12 months, some chloride ions migrated from the inner layer to the surface of the A specimen, and meanwhile, there was a slight increase in the surface chloride content of the B specimen; this may be due to that the low internal RH hampered the chloride migrating from A specimen to B specimen, and a long time exposure was needed to achieve the chloride migration in concrete. When the internal RH was $75 \%$ and $80 \%$, as shown in Figures 4(b) and 4(c), the chloride content in the A specimen generally decreased and the chloride content in the B specimen increased with increasing exposure duration; moreover, an obvious increase in the surface chloride content in the B specimen was observed when the exposure duration was 12 months; for example, the surface chloride content of the B specimen was, respectively, 0.027\%, 0.035\%, and $0.035 \%$ when the internal $\mathrm{RH}$ was $50 \%, 75 \%$, and $80 \%$ after 1 -month exposure and the results were $0.053 \%, 0.115 \%$, and $0.124 \%$ after 12 -month exposure.

Observing from Figure 4(d), when the internal $\mathrm{RH}$ was $100 \%$, there was an obvious decrease in the chloride content 


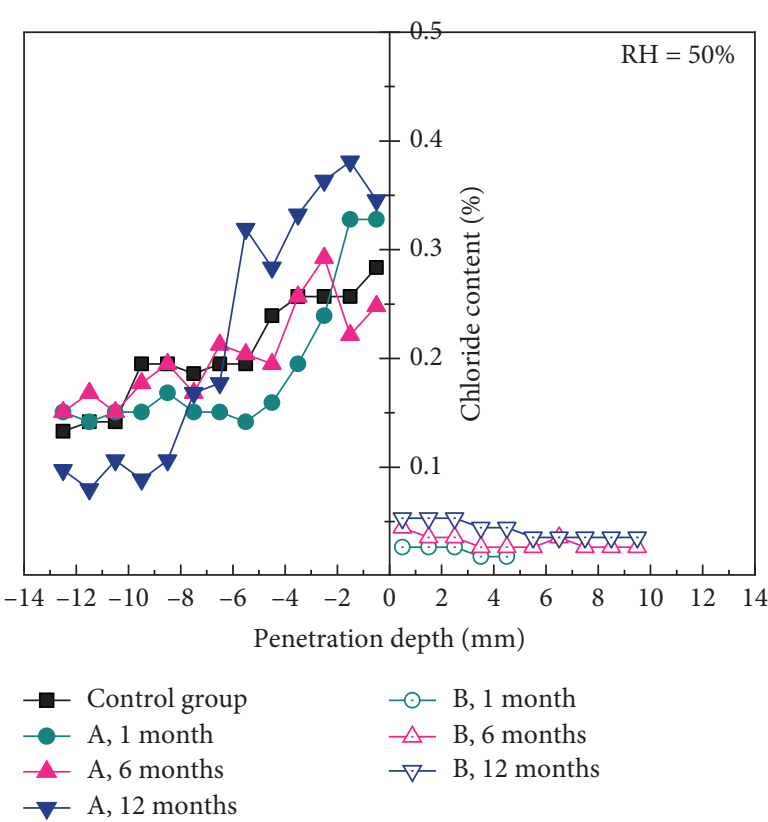

(a)

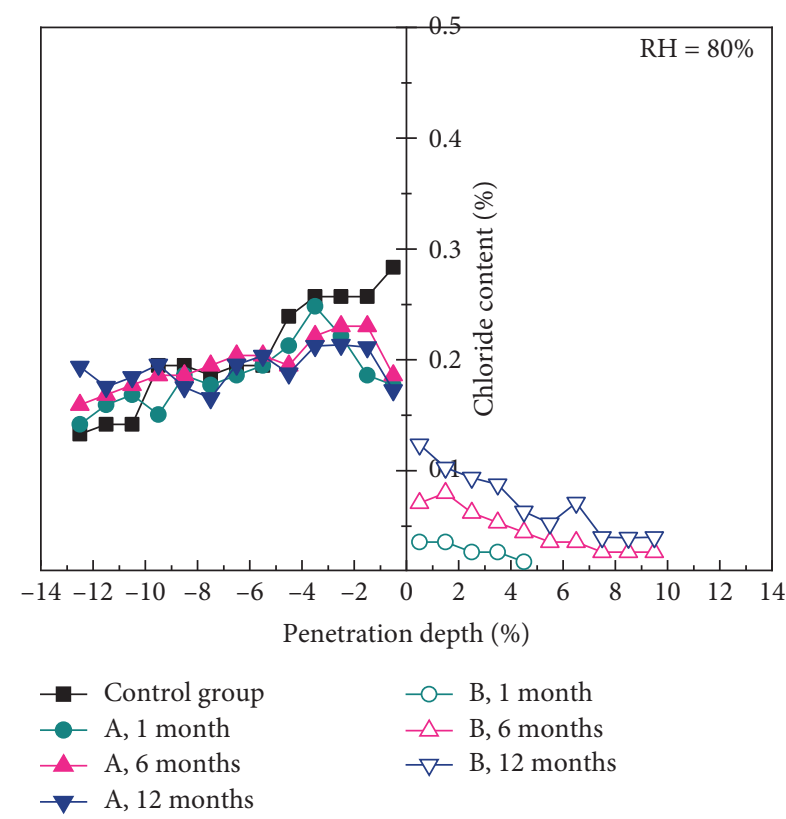

(c)

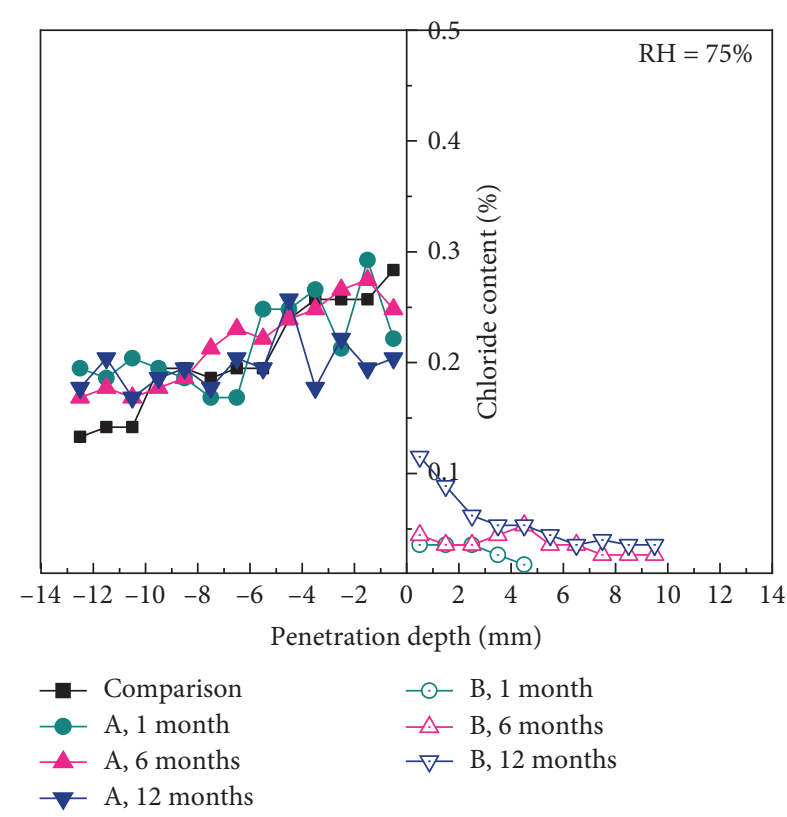

(b)

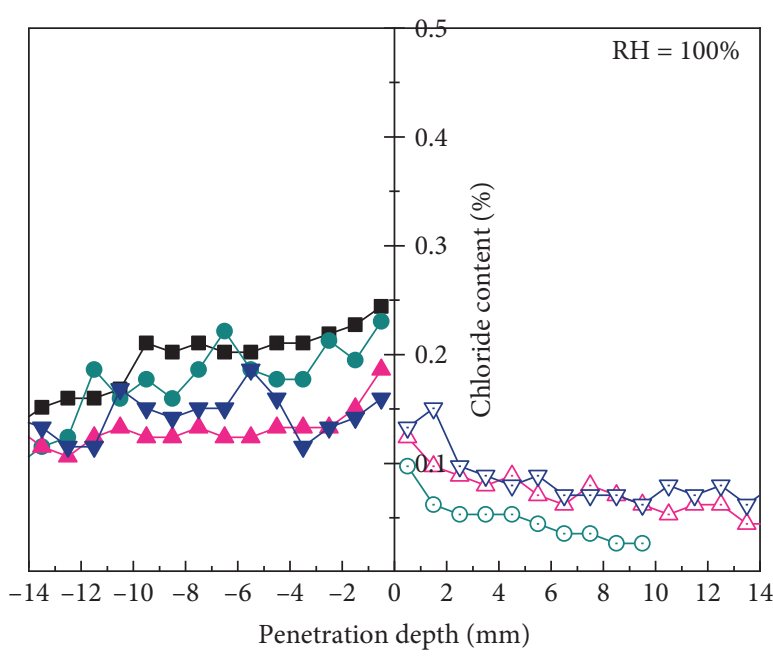

$-\odot-B, 1$ month

$-\triangle$ B, 6 months

$-\nabla$ B, 12 months

(d)

FiguRE 4: Chloride content curves of concrete with various internal $\mathrm{RH}$ (w/c=0.5). (a) $\mathrm{RH}=50 \%,(\mathrm{~b}) \mathrm{RH}=75 \%,(\mathrm{c}) \mathrm{RH}=80 \%$, (d) $\mathrm{RH}=100 \%$. Control group represents that the chloride content was immediately determined after the chloride attack test. The A specimen was initially saturated with $\mathrm{NaCl}$ solution; the $\mathrm{B}$ specimen was initially saturated with water; 1,6 , and 12 months were the connecting duration for $\mathrm{A}$ and $\mathrm{B}$ specimens.

of the A specimen with increasing exposure duration; moreover, the chloride content at various depths trended to be balanced, and this may be because the chloride rapidly migrated from high concentration to low concentration by concentration gradient when internal $\mathrm{RH}$ was $100 \%$, and finally a similar chloride content in various depths was reached. Some chloride ions migrated from the surface layer to the inner layer of the A specimen, and the other chloride ions migrated from A specimen to B specimen, which resulted in an obvious increase in the surface content of $B$ specimen. In addition, the surface and inner chloride content in the B specimen with $100 \% \mathrm{RH}$ was both higher than that with the other internal $\mathrm{RH}$, which was attributed to that the increasing internal $\mathrm{RH}$ promoted the chloride migration from the A specimen to $B$ specimen. When the exposure duration was the same, it was noticed that the difference value between the surface chloride content in A and $\mathrm{B}$ specimens decreased with increasing $\mathrm{RH}$, and the 
surface chloride content in A and B specimens was almost the same when the internal RH was $100 \%$.

Figure 5 shows the chloride content curves of concrete after various exposure durations. When the exposure duration was 1 month, the surface chloride content in the $\mathrm{B}$ specimen with $50 \% \mathrm{RH}, 75 \% \mathrm{RH}$, and $80 \% \mathrm{RH}$ was almost zero, whereas the surface chloride content with $100 \% \mathrm{RH}$ reached $0.1 \%$. When the exposure duration was 6 months, the surface chloride content in B specimen with $50 \% \mathrm{RH}$ and $75 \%$ $\mathrm{RH}$ was still lower than that with $80 \% \mathrm{RH}$ and $100 \% \mathrm{RH}$. When the exposure duration was 12 months, the surface and inner chloride content with $50 \%$ was much lower than that with $75 \% \mathrm{RH}, 80 \% \mathrm{RH}$, and $100 \% \mathrm{RH}$. For concrete with internal $\mathrm{RH}$ of above $75 \%$, the results above highlighted that the increasing internal $\mathrm{RH}$ was helpful to the chloride migration in concrete, and relatively low $\mathrm{RH}$ required more time to migrate enough chloride ion. Analyzing the reason was that the chloride penetration was mainly by the medium of water, the chloride penetration into concrete was mainly by massive water-saturated passageways [32-34]. The decreasing RH resulted in a decrease in the number of water-saturated passageways in concrete and thus the chloride migration was decreased. However, for the concrete with $50 \% \mathrm{RH}$, the prolonged exposure duration did not significantly increase the chloride penetration into the $\mathrm{B}$ specimen. This was because the capillary absorption force caused by unsaturated capillary pores, as well as the ion adsorption force between the C-S-H and chloride ion, further hindered the chloride migration in unsaturated concrete, and thus the chloride migration from the A specimen to B specimen with $50 \% \mathrm{RH}$ was quite slow.

Figure 6 further shows a relationship between the relative maximum chloride content and internal $\mathrm{RH}$ of concrete (B specimen), and a binomial relation could be observed. The increase in the maximum chloride content was slight when the internal $\mathrm{RH}$ ranged $50-75 \%$, and the increase was obvious when the internal $\mathrm{RH}$ was above $75 \%$. The specific equation was also described in this figure, where $C_{\mathrm{Rmax}}$ was the relative value of the maximum chloride concrete in \%; RH was the internal relative humidity, in $\%$.

\subsection{Chloride Penetration into Concrete when Subjected to} Various External RH Values. Figure 7(a) shows the chloride content curves of concrete subjected to the condition with $50 \% \mathrm{RH}$. When the exposure duration was 1 month, the surface and maximum chloride content after 1 month was higher than the control group without exposure; this was because the water evaporation resulted in the chloride migration from inner to surface layer. However, when the exposure duration was 12 months, the surface and maximum chloride content after 12 months was lower than the control group; this was due to that the water convection was decreased with increasing exposure duration and chloride ion migration from the high concentration to the low concentration by concentration gradient, which resulted in a decrease in the surface chloride content and an increase in the inner layer of concrete, such as the maximum chloride content after 6 and 12 months was 5.3\% and 26.4\% lower than that after 1 month.
Figures $7(\mathrm{~b})-7(\mathrm{~d})$ show the chloride content curves of concrete exposed to the environment with $75-100 \% \mathrm{RH}$. It was noticed that the maximum chloride content decreased with increasing exposure duration; for example, the maximum chloride content of concrete subjected to $75-100 \% \mathrm{RH}$ was $17.6-20.5 \%$ lower than the control group when the exposure duration was 1 month, and the results were 42.0-54.5\% when the exposure duration was 12 months. Furthermore, the chloride content in inner layer decreased with increasing exposure duration; for example, the balanced chloride content of concrete subjected to $75-100 \% \mathrm{RH}$ was $31.2-40.6 \%$ higher than of the control group when the exposure duration was 1 month, and the results were $122.5-134.4 \%$ when the exposure duration was 12 months.

The results above highlighted that external $\mathrm{RH}$ had an obvious impact on the chloride penetration into concrete. When the external $\mathrm{RH}$ was $50 \%$, the water evaporation at the early exposure played a dominant role in the chloride migration, and the water evaporation decreased with increasing exposure duration, and the chloride migration by concentration gradient began to play a key role in the chloride penetration at the latter period of air exposure. However, when the external $\mathrm{RH}$ was above $75 \%$, the chloride migration by concentration gradient played a dominant role in chloride migration at the early and latter stages of air exposure and the chloride ion migrated from high concentration to low concentration, which resulted in a decrease in the surface content and an increase in the chloride content in the inner layer of concrete. Especially for concrete subjected to $75-100 \% \mathrm{RH}$, the chloride content on the surface layer and in the inner layer was almost the same after 12-month exposures, and this phenomenon was not observed for concrete subjected to $50 \% \mathrm{RH}$. Figure 8 shows the balanced chloride content in the inner layer of concrete when subjected to various external $\mathrm{RH}$ values. The balanced chloride content increased obviously at the first exposure duration, and then the increase became slow with the further increase of exposure duration. In addition, the difference value between the balanced chloride content with $50 \% \mathrm{RH}$ and that with $75-100 \%$ RH was significant with increasing exposure duration.

Figure 9 shows the chloride content curves of concrete after various exposure durations. At the early period of air exposure (1 month), the water evaporation resulted in the chloride migration from the inner layer to the surface layer in concrete, and in this case, the maximum chloride content in concrete subjected to $50-80 \%$ RH was higher than that subjected to $100 \% \mathrm{RH}$, and even the maximum chloride content in concrete with $50 \% \mathrm{RH}$ was higher than the control group without exposing to external environment. At the latter period of air exposure (12 months), the internal $\mathrm{RH}$ in concrete tends to be close to the external $\mathrm{RH}$ (50\%), and there was no obvious difference on the chloride distribution in concrete after environment exposure and the control group, which further proved that the chloride migration was difficult to happen in concrete with low $\mathrm{RH}$. However, when the external RH was $75-100 \%$, the chloride content in the surface and inner layer was tended to be the same, and in this case, the concentration gradient provided 

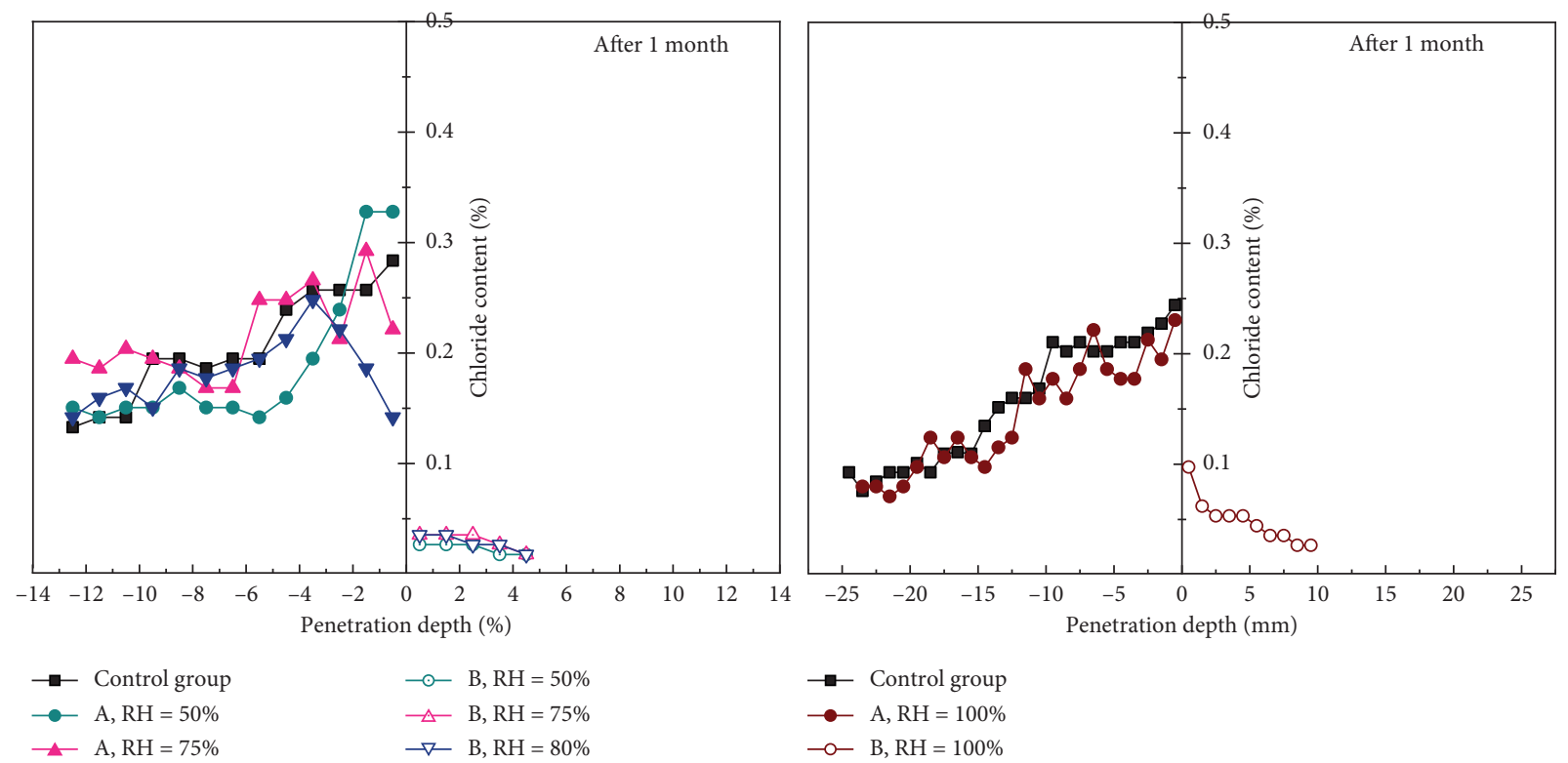

$\rightarrow$ Control group

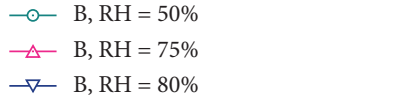

- $\mathrm{A}, \mathrm{RH}=100 \%$

- A, RH $=75 \%$

$\rightarrow-\mathrm{B}, \mathrm{RH}=80 \%$

(a)
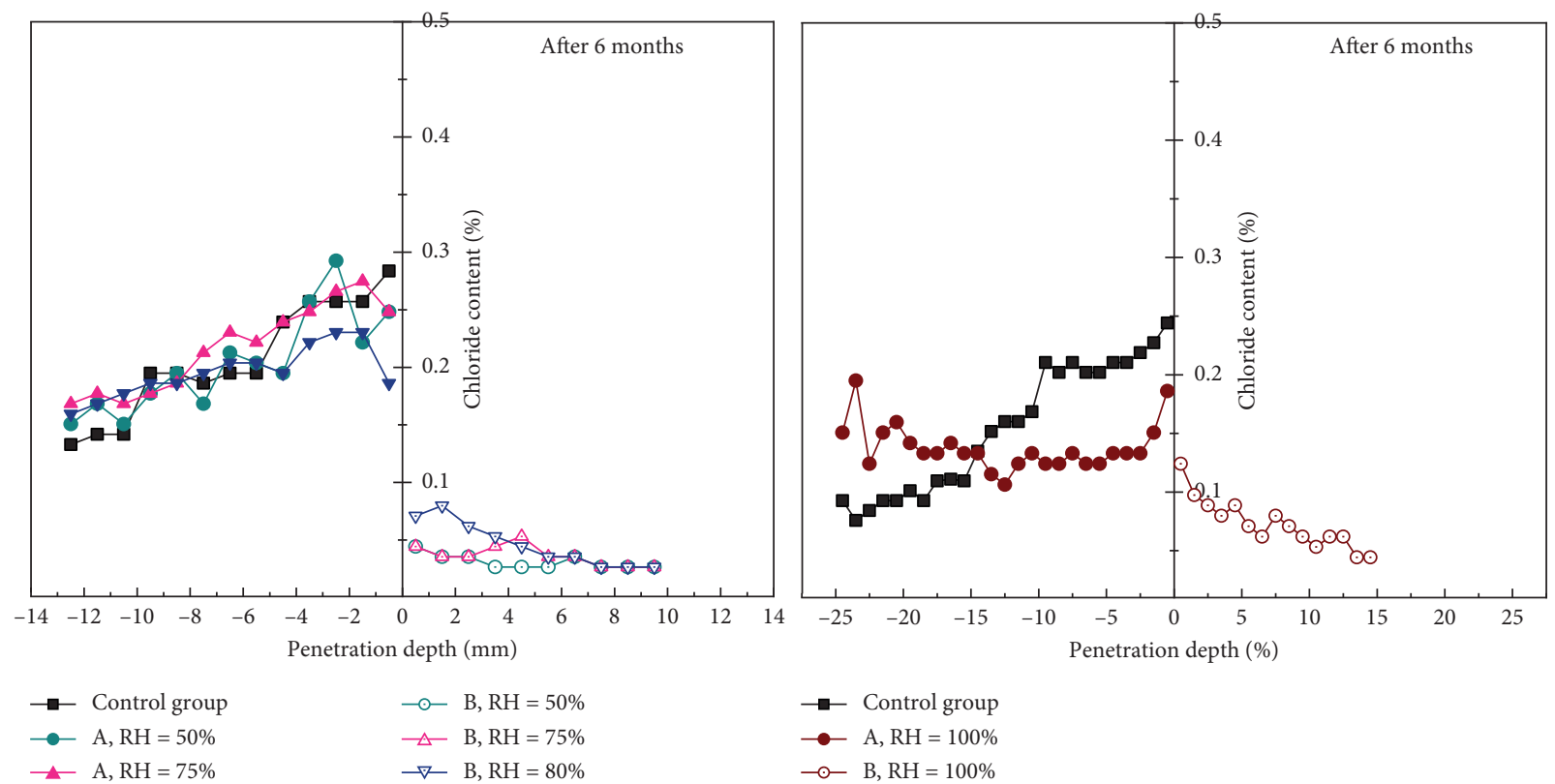

(b)

Figure 5: Continued. 

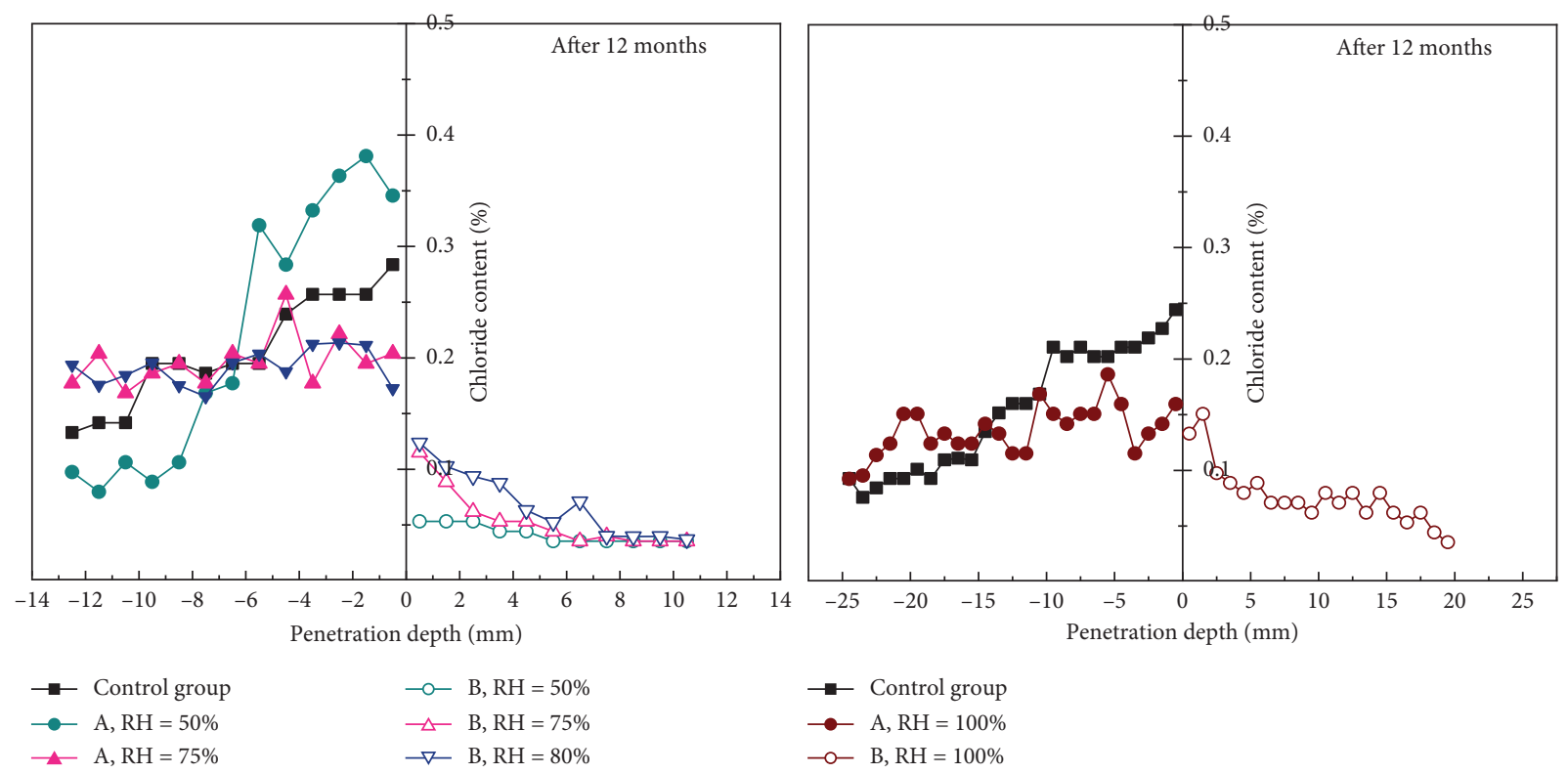

$\rightarrow-$ Control group

$\longrightarrow \mathrm{A}, \mathrm{RH}=50 \%$

- $\mathrm{A}, \mathrm{RH}=75 \%$

$\rightarrow \mathrm{A}, \mathrm{RH}=80 \%$

$$
\begin{aligned}
& \multimap-B, \text { RH }=50 \% \\
& -\square \text { B, RH }=75 \% \\
& -\quad \text { B, RH }=80 \%
\end{aligned}
$$

$-\mathrm{B}, \mathrm{RH}=100 \%$

(c)

FIGURE 5: Chloride content curves of concrete with various exposure durations (w/c=0.5). (a) 1 month, (b) 6 months, and (c) 12 months.

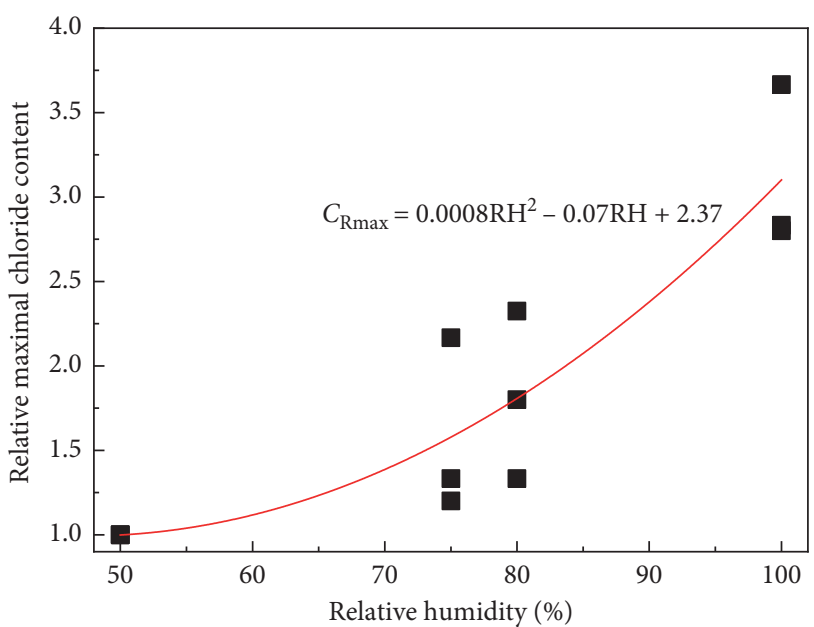

FIgURE 6: Relationship between the relative maximum chloride content and internal $\mathrm{RH}$ of concrete.

the driving force for chloride migration from high concentration to low concentration. It was noticed that the difference value on the surface and inner chloride content was decreased with increasing external $\mathrm{RH}$, which indicated that the high external RH promoted the chloride migration by a concentration gradient. Figure 9 (d) shows a relationship between the balanced chloride content in inner layer and the exposed external $\mathrm{RH}$ after various exposure durations, and a linear relationship could be observed between them; moreover, the specific equation was also described in this figure, where $C_{\mathrm{SA}}$ was the chloride content at stability area of concrete, in \%; RH was the external $\mathrm{RH}$, in \%.
3.3. Chloride Migration in Concrete with the Coupling of Water Convection. Simulating the chloride migration under wetdry cycling, the chloride content in concrete was determined after various durations of water convection. Observing from Figures 10(a) and 10(c), when the chloride attack duration was 2 weeks, in this case, there was no enough chloride ion present in concrete. The surface chloride content increased with increasing duration of water convection up to 8 months; this was because the water convection resulted in the chloride migration from the inner to surface layer. When the duration of water convection was 16 months, the surface chloride content in concrete with $0.4 \mathrm{w} / \mathrm{c}$ was high than that after $0-8$ months; this may be due to that the concrete with low w/c had high density and the water convection was steady with water evaporation, and thus the chloride continued steadily migrating from the inner to the surface layer in concrete. However for concrete with $0.6 \mathrm{w} / \mathrm{c}$, the surface chloride content in concrete after 16 months was lower than that after 0-8 months; this was because the concrete with high $\mathrm{w} / \mathrm{c}$ had high porosity, and the rapid water evaporation resulted in the separation of $\mathrm{NaCl}$ crystal on the surface; thus, the surface chloride content was decreased.

Observing from Figures 10 (b) and 10(d), there was enough chloride ion contained in concrete when the chloride attack duration was 16 weeks. When the duration of water convection was 2 weeks, the surface chloride content in concrete with 0.4 and $0.6 \mathrm{w} / \mathrm{c}$ was both higher than that of the control group, which was attributed to that the water convection promoted the chloride migration from the inner to surface layer. However, when the duration of water convection was above 8 weeks, the surface chloride content in concrete with 0.4 and $0.6 \mathrm{w} / \mathrm{c}$ was both lower than that of 


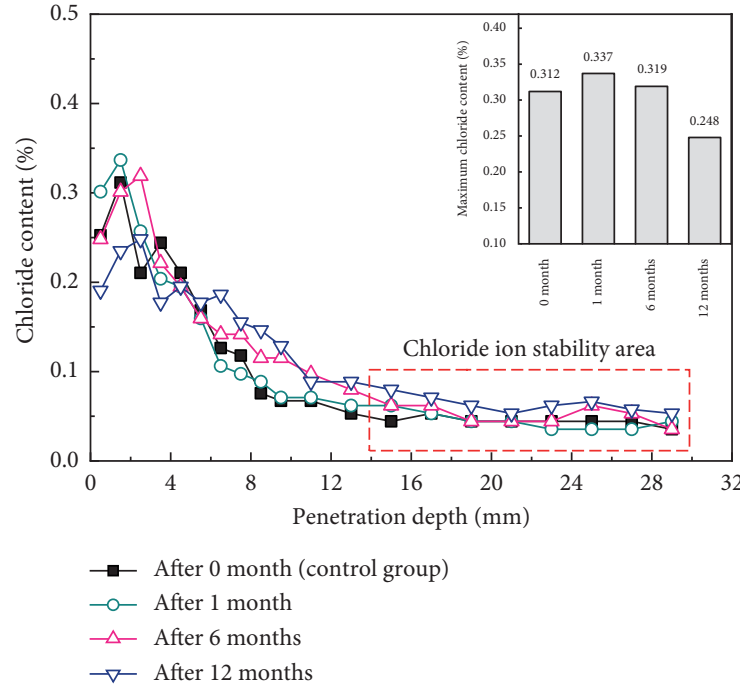

(a)

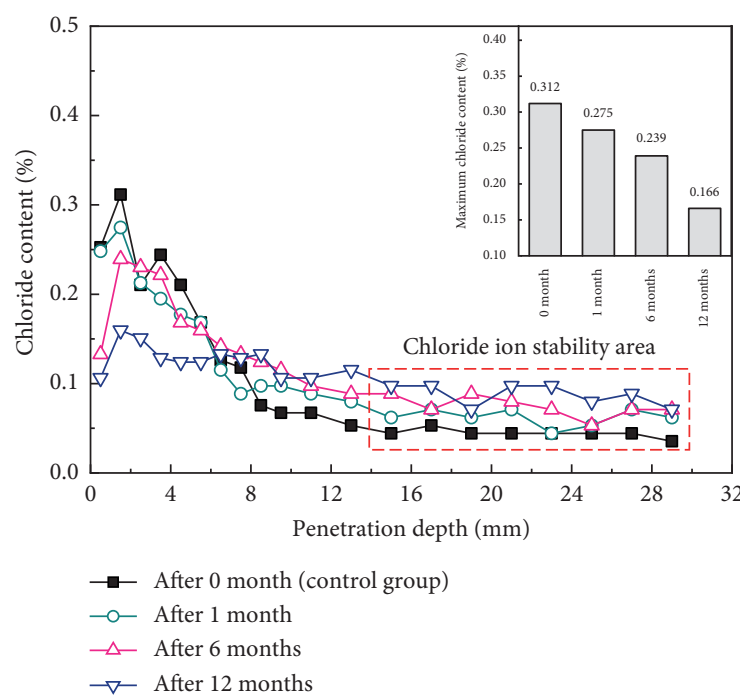

(c)

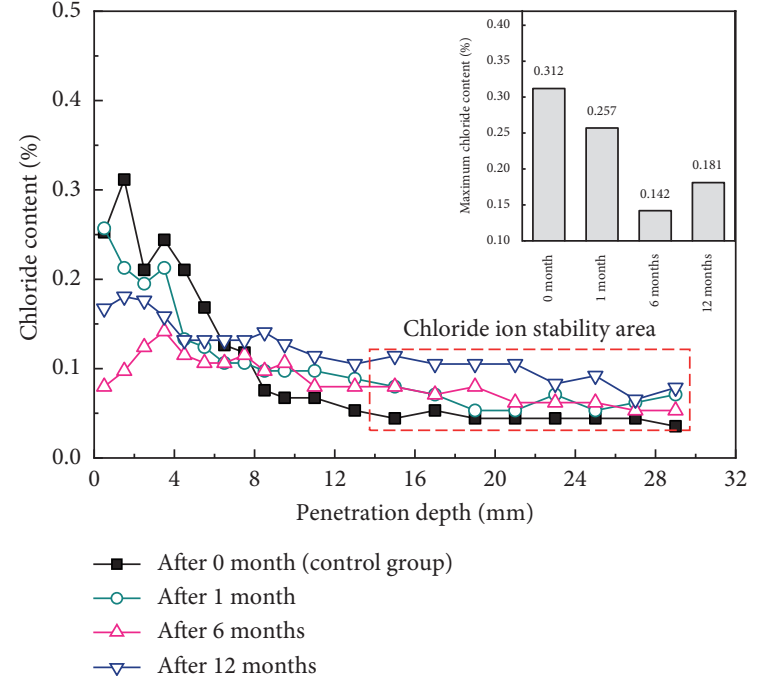

(b)

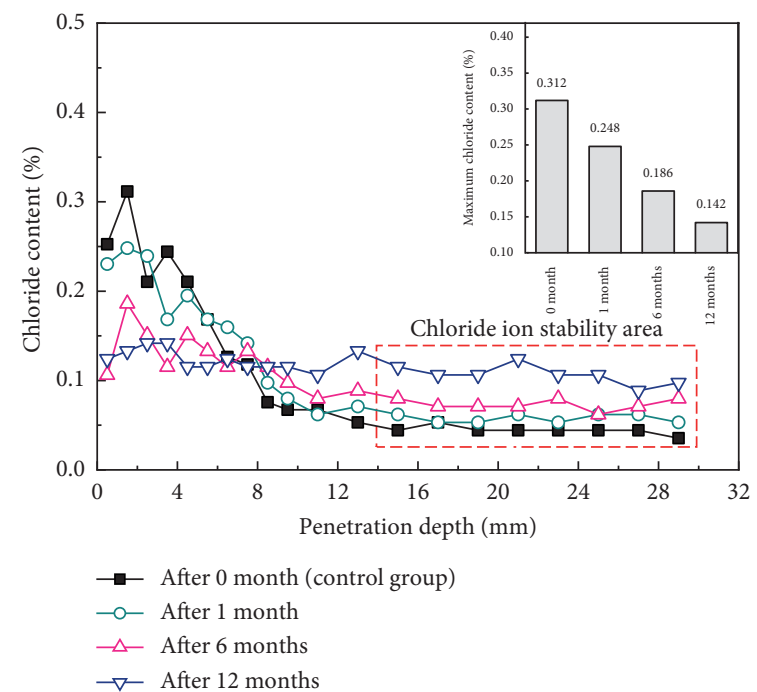

(d)

Figure 7: Chloride content curves for concrete subjected to various external $\mathrm{RH}$ values (w/c $=0.5)$. (a) $\mathrm{RH}=50 \%$, (b) $\mathrm{RH}=75 \%$, (c) $\mathrm{RH}=80 \%$, and (d) $\mathrm{RH}=100 \%$. Control group represents that the chloride content was immediately determined after chloride attack.

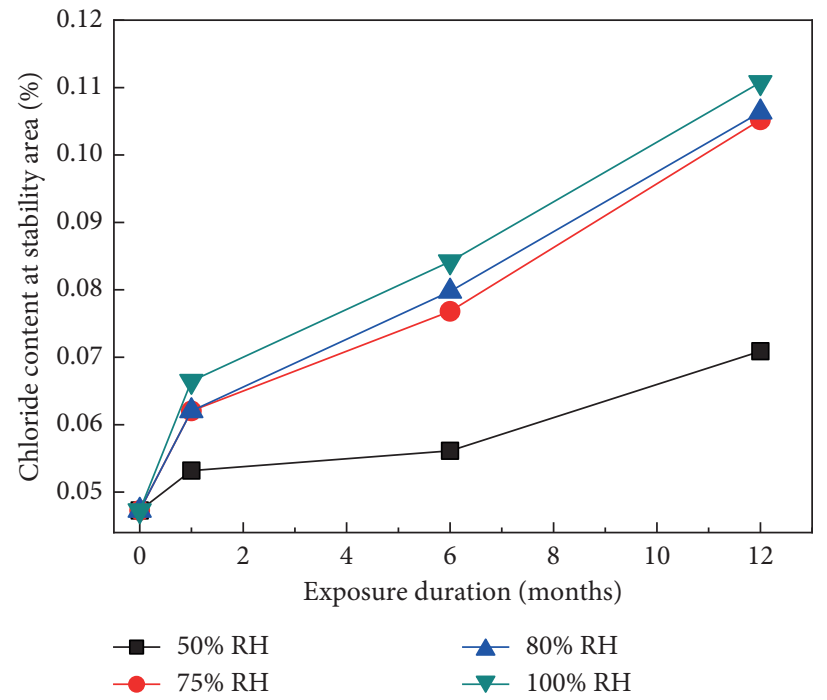

FIGURE 8: Balanced chloride content in concrete subjected to various external RH values. 


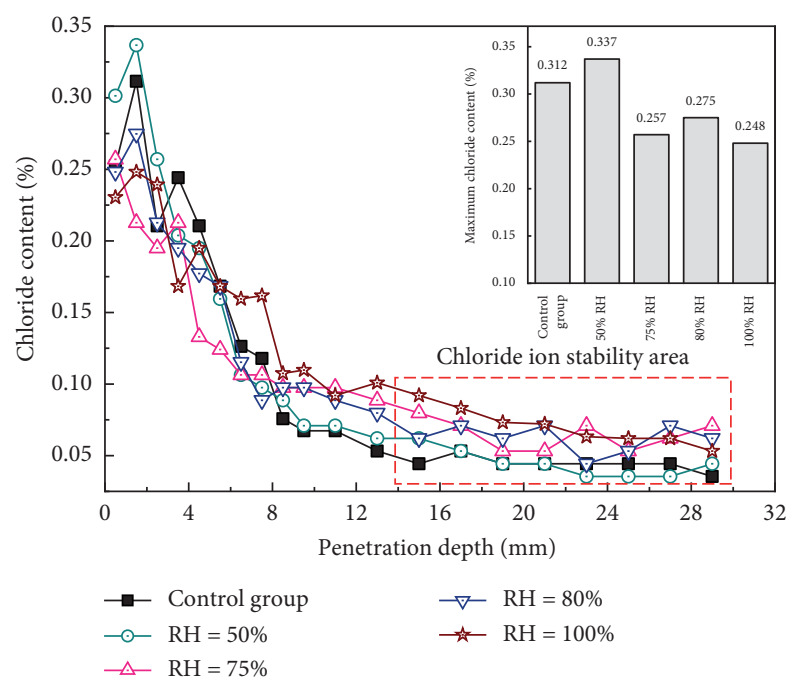

(a)

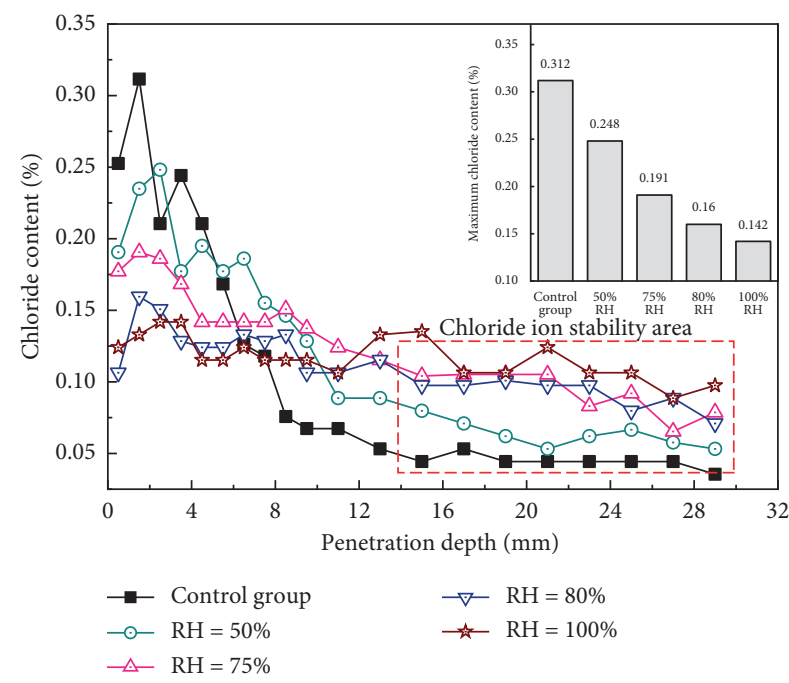

(c)

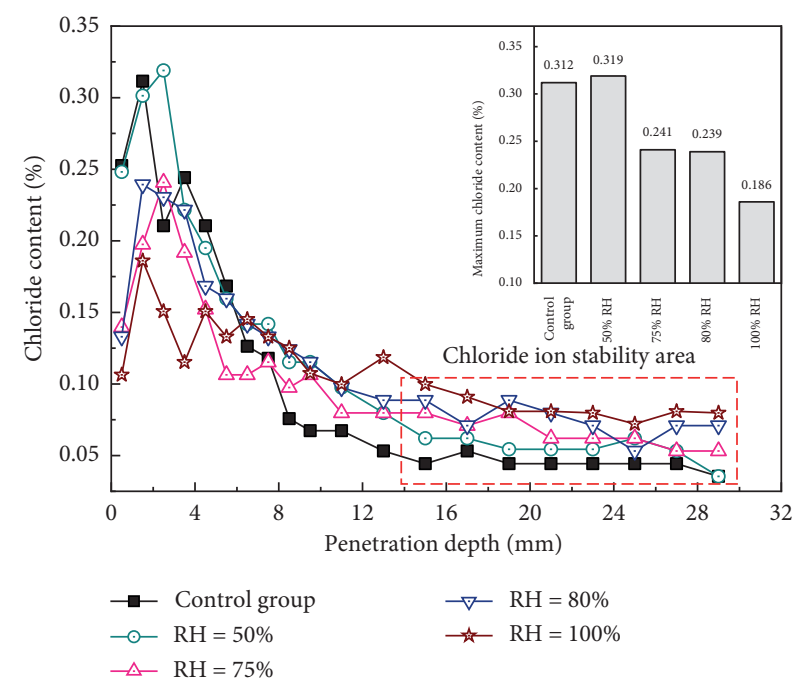

(b)

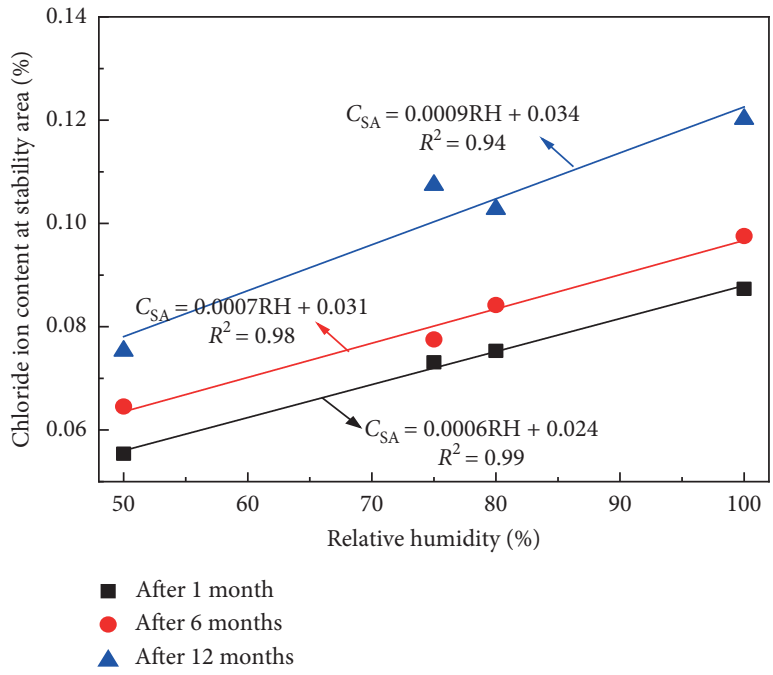

(d)

FIGURE 9: Chloride content curves of concrete after various exposure durations (w/c = 0.5). (a) After 1 month, (b) after 6 months, (c) after 12 months, and (d) relationship. Control group represents that the chloride content was immediately determined after chloride attack.

the control group, and a contrary phenomenon was observed for the inner chloride content.

On the one side, when the concrete contained enough chloride ion, the separation of $\mathrm{NaCl}$ crystal could be observed on the surface of concrete with continuous water evaporation, which decreased the surface chloride content; moreover, the decrease in the surface chloride content of concrete with $0.6 \mathrm{w} / \mathrm{c}$ was more obvious than that with $0.4 \mathrm{w} /$ c. On the other side, the chloride migration was easy to happen when enough chloride was contained in concrete, which resulted in the chloride migration from the surface layer (high concentration) to the inner layer (low concentration). In particular, the surface and inner chloride content in concrete with $0.6 \mathrm{w} / \mathrm{c}$ was close when the water convection duration was 16 weeks, and the inner chloride content in such concrete was much higher than the control group. The results above showed that the water convection played a key role in the chloride migration in concrete, and the change was more obvious for the chloride content in the surface layer; however, with the further increase of water convection duration, the chloride migration by concentration gradient resulted in an increase in the inner chloride content of concrete. Compared with the results in Figures 10(b) and $10(\mathrm{~d})$, the effect of water convection and concentration gradient on chloride migration in concrete with high w/c was much higher than that with low w/c. The results above highlighted that the concrete properties (w/c), chloride attack duration, and water convection duration all had an obvious impact on the chloride distribution in concrete, which should be seriously considered in the test of wet-dry cycle.

Figures 11(a) and 11(b) show a comparison between the chloride penetration by convection and concentration gradient when the concrete $\mathrm{w} / \mathrm{c}$ was 0.4 . The surface chloride 


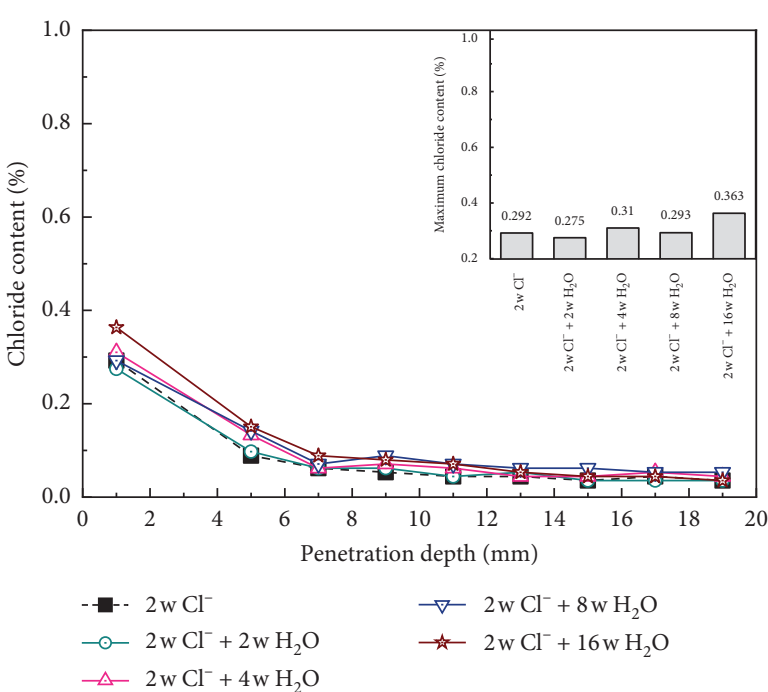

(a)

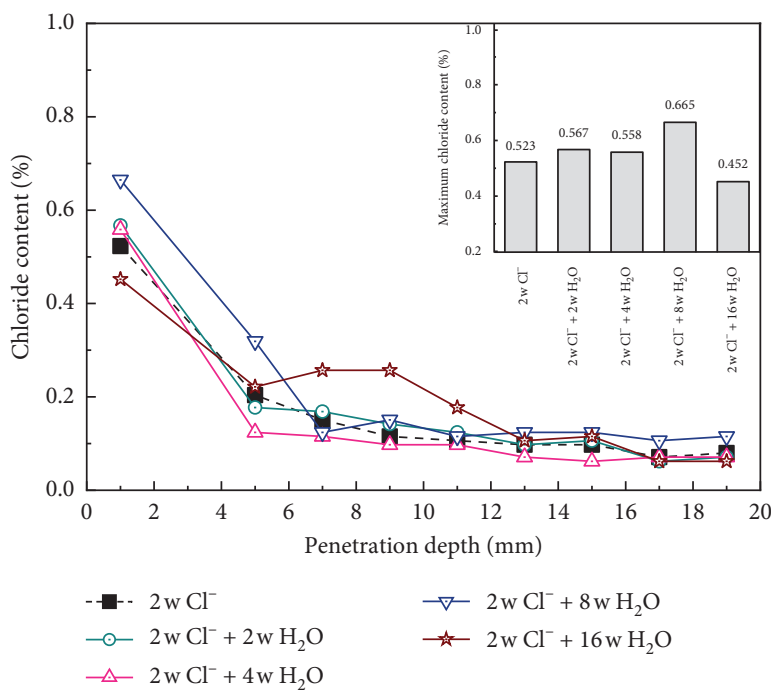

(c)

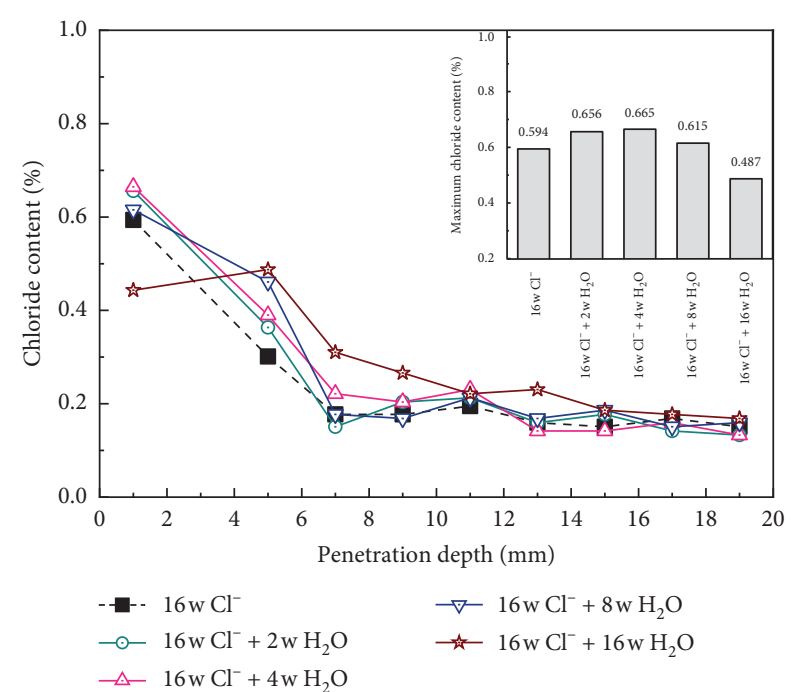

(b)

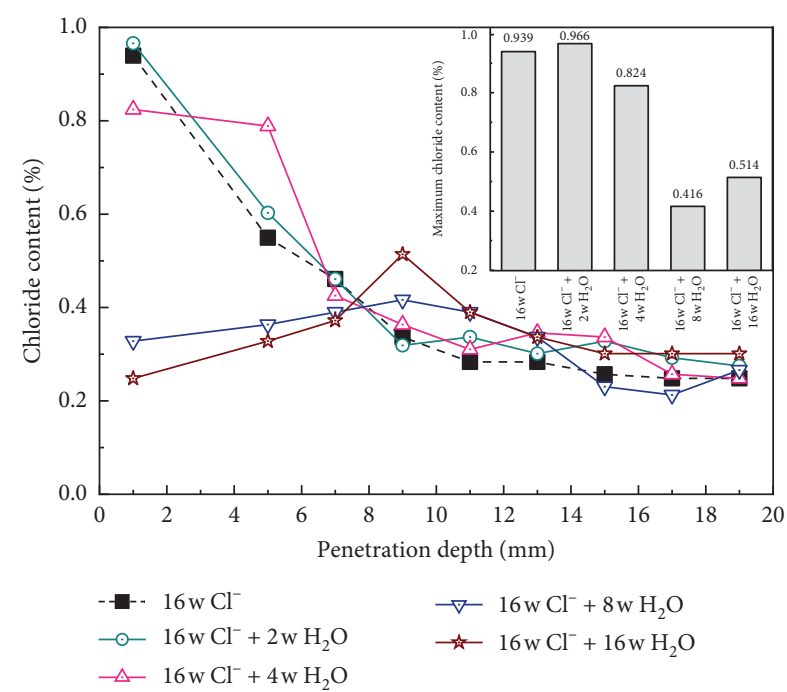

(d)

FIGURE 10: Chloride content curves of concrete after chloride attack and water convection time. (a) After 2-week chloride attack (w/c $=0.4$ ), (b) after 16-week chloride attack $(w / c=0.4),(c)$ after 2-week chloride attack $(w / c=0.6)$, and $(d)$ after 16-week chloride attack $(w / c=0.6)$. " $2 \mathrm{w} \mathrm{Cl}^{-}$" represents that chloride content was immediately determined after 2-week chloride attack (control group); " $2 \mathrm{w} \mathrm{Cl}{ }^{-}+16 \mathrm{w} \mathrm{H}_{2} \mathrm{O}$ " presents that the concrete was first subjected to the chloride attack for 2 weeks and then the opposite surface connected with water for 16 weeks.

content by convection was higher than that by concentration gradient after the same duration; moreover, the difference on the surface chloride content by convection and concentration gradient after 2 weeks was more obvious than that after 16 weeks. However, there was no obvious difference on the inner chloride content by convection and concentration gradient. This was because that the effect of water convection on the chloride distribution was obvious when the chloride penetration depths were below $6 \mathrm{~mm}$, whereas the effect of chloride migration by the concentration gradient on chloride distribution was significant in the inner concrete. The intensity by convection was higher than that by a concentration gradient, and the continuous convection resulted in the chloride gathering around the surface layer with water evaporation, which led to the chloride content by convection was higher than that by concentration gradient [35]. However, the water convection was feeble in the inner layer of concrete, and thus there was no obvious difference on the inner chloride content in various concrete after the same duration.

Observing from Figures 11(a)-11(d), when the chloride attack duration was 2 weeks and there was no enough chloride ion in concrete, the surface chloride content by convection was higher than that by a concentration gradient. However, when the chloride attack duration was 16 weeks and there was enough chloride ion in concrete, the surface chloride content by convection was lower than that by concentration gradient, and this was because of the separation of $\mathrm{NaCl}$ crystal on the surface layer with continuous 


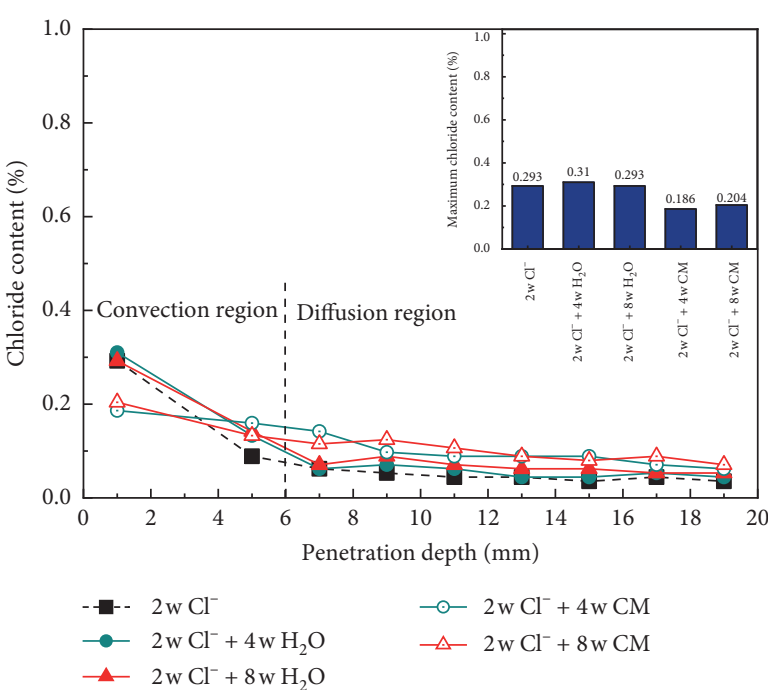

(a)

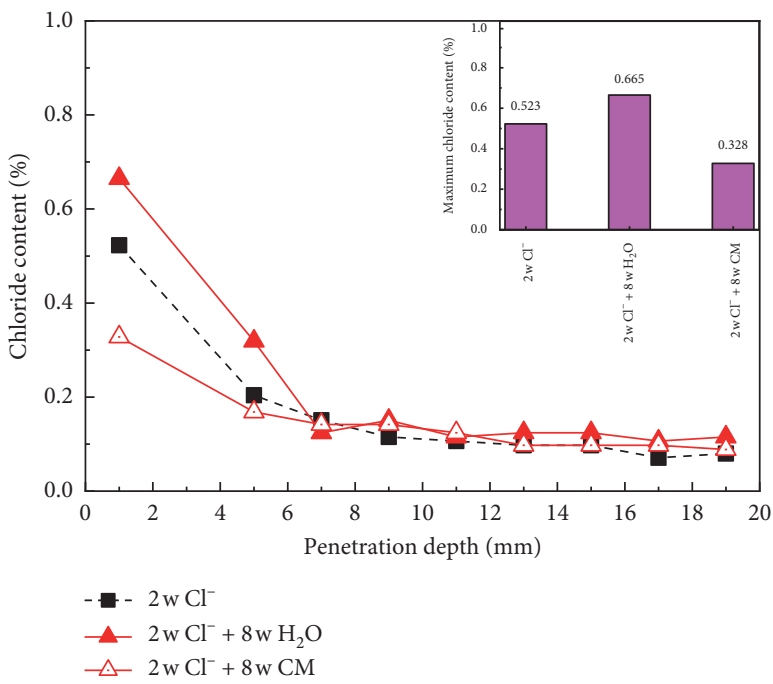

(c)

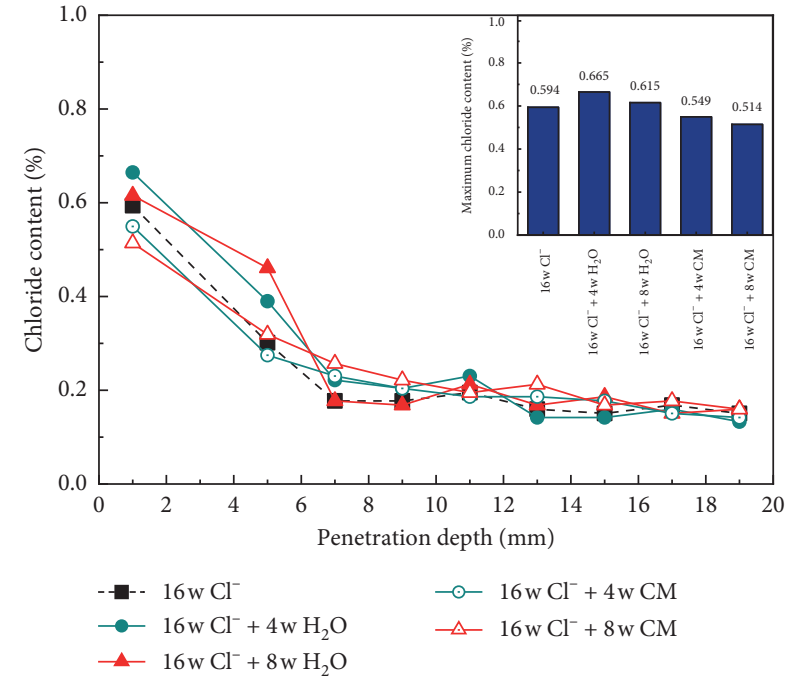

(b)

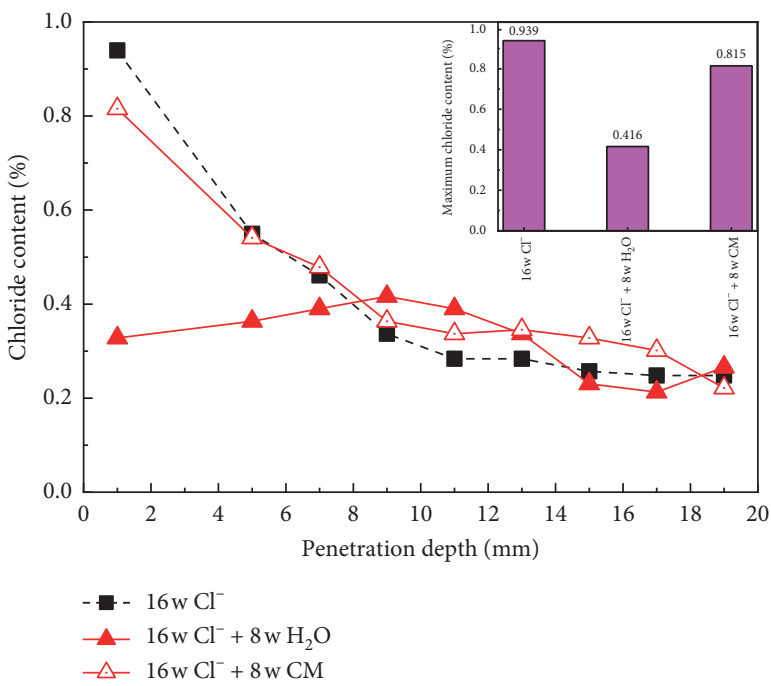

(d)

FIGURE 11: Curves of chloride content by convection and concentration gradient. (a) After 2 -week chloride attack (w/c $=0.4)$, (b) after 16week chloride attack $(\mathrm{w} / \mathrm{c}=0.4),(\mathrm{c})$ after 2 -week chloride attack $(\mathrm{w} / \mathrm{c}=0.6)$, and $(\mathrm{d})$ after 16 -week chloride attack $(\mathrm{w} / \mathrm{c}=0.6)$. " $2 \mathrm{w} \mathrm{Cl}^{-}$" represents that chloride content was immediately determined after 2 -week chloride attack (control group); " $2 \mathrm{w} \mathrm{Cl}^{-}+8 \mathrm{w} \mathrm{CM}$ " presents that the concrete was first subjected to the chloride attack for 2 weeks, and then all the surfaces were sealed and standing for 8 weeks, and in this case, chloride migration (CM) was by the concentration gradient.

water evaporation. In addition, the separation of $\mathrm{NaCl}$ crystal was prone to happen in concrete with high $\mathrm{w} / \mathrm{c}$ than that with low w/c; moreover, the initial chloride content in concrete with high w/c was higher than that with low w/c, which further aggravated the chloride precipitation on surface and meanwhile migration to the inner layer. Therefore, the surface chloride content by convection was higher than that by a concentration gradient in concrete with $0.4 \mathrm{w} / \mathrm{c}$, whereas an opposite result was obtained for concrete with $0.6 \mathrm{w} / \mathrm{c}$. The results above highlighted that the concrete properties $(\mathrm{w} / \mathrm{c})$, chloride attack duration, and water convection duration were the main reason that resulted in an obvious difference on the chloride penetration by convection and concentration gradient.
This paper provided an insight into the impact of internal and external $\mathrm{RH}$ on the chloride penetration into concrete. It was noted that the results and discussion were based on the macroscopic experimental results in this paper. The macroproperties was closely related to the microproperties of cementitious materials [36-38], and thus further microscopic test and analysis should be conducted to achieve a better understanding on the chloride migration mechanism in unsaturated concrete. In addition, considering the wide use of recycled concrete in construction engineering [39-41], the chloride penetration into recycled concrete under the coupling effects of internal moisture content and external RH should be investigated in further. 


\section{Conclusions}

Concrete was inevitably subjected to various environments, and this paper was developed to quantify the effects of internal moisture content and external $\mathrm{RH}$ on the chloride migration in an unsaturated concrete. Based on the results and discussion above, following conclusions were obtained:

(1) Chloride migration was difficult to happen in concrete with internal $\mathrm{RH}$ below 50\%. However, the chloride ion rapidly migrated in concrete when its internal $\mathrm{RH}$ was above $75 \%$, and chloride penetration rate increased with increasing internal RH. In particular, a good relationship was observed between the maximum chloride content and internal moisture content of concrete.

(2) When concrete suffered chloride attack and then exposed to the environment with $\mathrm{RH}$ below $50 \%$, the chloride migration from the inner to the surface layer was more obvious than that from the surface layer to the inner layer, and an obvious increase in the surface chloride content could be observed in concrete at the early period of exposure. However for the concrete subjected to the external $\mathrm{RH}$ above $75 \%$, the chloride migration by concentration difference played a key role in the chloride distribution in concrete, and the surface chloride content decreased and the inner chloride content increased with increasing exposure duration; finally, the chloride content in surface layer and inner layer was tended to be the same.

(3) For chloride migration under the coupling effect of water convection, the chloride migration was significantly impact by the water convection when the chloride penetration depth was below $6 \mathrm{~mm}$, whereas the chloride migration by concentration difference played a leading role in the chloride distribution in the inner layer of concrete (above $6 \mathrm{~mm}$ ). The concrete properties $(\mathrm{w} / \mathrm{c})$, chloride attack duration, and water convection duration all had an obvious impact on the chloride distribution in concrete, and there was an obvious difference on the chloride distribution by water convection and concentration gradient.

\section{Data Availability}

We confirm the data are available in this manuscript. The data in this manuscript were obtained through a series of tests. The related data used to support the findings of this study are available from the corresponding author upon request.

\section{Conflicts of Interest}

We confirm that there are no any conflicts of interest in this paper.

\section{Acknowledgments}

The authors gratefully acknowledge the substantial support of ongoing projects titled "Project 333" of Jiangsu Province
(BRA2017273) and China Postdoctoral Science Foundation (2019M651579).

\section{References}

[1] P. Zhang, F. H. Wittmann, P. Lura, H. S. Müller, S. Han, and T. Zhao, "Application of neutron imaging to investigate fundamental aspects of durability of cement-based materials: a review," Cement and Concrete Research, vol. 108, pp. 152166, 2018.

[2] Z. Ma, M. Liu, Q. Tang, C. Liang, and Z. Duan, "Chloride permeability of recycled aggregate concrete under the coupling effect of freezing-thawing, elevated temperature or mechanical damage," Construction and Building Materials, vol. 237, Article ID 117648, 2020.

[3] C. Liang, H. Ma, Y. Pan, Z. Ma, Z. Duan, and Z. He, "Chloride permeability and the caused steel corrosion in the concrete with carbonated recycled aggregate," Construction and Building Materials, vol. 218, pp. 506-518, 2019.

[4] J. M. Wachira, R. Wangui Ngari, J. K. Thiong'o, and J. M. Marangu, "Effect of sulphate and chloride ingress on selected cements mortar prisms immersed in seawater and leather industry effluent," Advances in Civil Engineering, vol. 2019, Article ID 8191689, 16 pages, 2019.

[5] P. Zhang, D. Li, Y. Qiao, S. Zhang, C. Sun, and T. Zhao, "Effect of air entrainment on the mechanical properties, chloride migration, and microstructure of ordinary concrete and fly ash concrete," Journal of Materials in Civil Engineering, vol. 30, no. 10, Article ID 04018265, 2018.

[6] Z. Ma, W. Li, H. Wu, and C. Cao, "Chloride permeability of concrete mixed with activity recycled powder obtained from C\&D waste," Construction and Building Materials, vol. 199, pp. 652-663, 2019.

[7] P. Zhang, F. H. Wittmann, M. Vogel, H. S. Müller, and T. Zhao, "Influence of freeze-thaw cycles on capillary absorption and chloride penetration into concrete," Cement and Concrete Research, vol. 100, pp. 60-67, 2017.

[8] J. Bao, S. Li, P. Zhang et al., "Influence of the incorporation of recycled coarse aggregate on water absorption and chloride penetration into concrete," Construction and Building Materials, vol. 239, Article ID 117845, 2020.

[9] C. Qiao, A. T. Coyle, O. B. Isgor, and W. J. Weiss, "Prediction of chloride ingress in saturated concrete using formation factor and chloride binding isotherm," Advances in Civil Engineering Materials, vol. 7, no. 1, pp. 206-220, 2018.

[10] Y. Cao, C. Gehlen, U. Angst, L. Wang, Z. Wang, and Y. Yao, "Critical chloride content in reinforced concrete-an updated review considering Chinese experience," Cement and Concrete Research, vol. 117, pp. 58-68, 2019.

[11] A. Petcherdchoo, "Closed-form solutions for modeling chloride transport in unsaturated concrete under wet-dry cycles of chloride attack," Construction and Building Materials, vol. 176, pp. 638-651, 2018.

[12] C. Sun, L. Yuan, X. Zhai, F. Qu, Y. Li, and B. Hou, "Numerical and experimental study of moisture and chloride transport in unsaturated concrete," Construction and Building Materials, vol. 189, pp. 1067-1075, 2018.

[13] Y. Zhang, G. Ye, and Z. Yang, "New insights into long-term chloride transport in unsaturated cementitious materials: role of degree of water saturation," Construction and Building Materials, vol. 238, Article ID 117677, 2020.

[14] G. Barluenga, C. Guardia, and J. Puentes, "Effect of curing temperature and relative humidity on early age and hardened 
properties of SCC," Construction and Building Materials, vol. 167, pp. 235-242, 2018.

[15] Y. Han, J. Zhang, Y. Luosun, and T. Hao, "Effect of internal curing on internal relative humidity and shrinkage of high strength concrete slabs," Construction and Building Materials, vol. 61, pp. 41-49, 2014.

[16] Ç. Yalçınkaya and H. Yazıcı, "Effects of ambient temperature and relative humidity on early-age shrinkage of UHPC with high-volume mineral admixtures," Construction and Building Materials, vol. 144, pp. 252-259, 2017.

[17] J. Frech-Baronet, L. Sorelli, and J.-P. Charron, "New evidences on the effect of the internal relative humidity on the creep and relaxation behaviour of a cement paste by micro-indentation techniques," Cement and Concrete Research, vol. 91, pp. 3951, 2017.

[18] A. Leemann and F. Moro, "Carbonation of concrete: the role of $\mathrm{CO}_{2}$ concentration, relative humidity and $\mathrm{CO}_{2}$ buffer capacity," Materials and Structures, vol. 50, no. 1, Article ID 30, 2017.

[19] C. Liang, B. Pan, Z. Ma, Z. He, and Z. Duan, "Utilization of $\mathrm{CO}_{2}$ curing to enhance the properties of recycled aggregate and prepared concrete: a review," Cement and Concrete Composites, vol. 105, Article ID 103446, 2020.

[20] B. Zhan, C. S. Poon, Q. Liu, S. Kou, and C. Shi, "Experimental study on $\mathrm{CO}_{2}$ curing for enhancement of recycled aggregate properties," Construction and Building Materials, vol. 67, pp. 3-7, 2014.

[21] L. Homan, A. N. Ababneh, and Y. Xi, "The effect of moisture transport on chloride penetration in concrete," Construction and Building Materials, vol. 125, pp. 1189-1195, 2016.

[22] P. Liu, Z. Yu, Z. Lu, Y. Chen, and X. Liu, "Predictive convection zone depth of chloride in concrete under chloride environment," Cement and Concrete Composites, vol. 72, pp. 257-267, 2016.

[23] E. Bastidas-Arteaga, A. Chateauneuf, M. Sánchez-Silva, P. Bressolette, and F. Schoefs, "A comprehensive probabilistic model of chloride ingress in unsaturated concrete," Engineering Structures, vol. 33, no. 3, pp. 720-730, 2011.

[24] E. Samson, J. Marchand, K. A. Snyder, and J. J. Beaudoin, "Modeling ion and fluid transport in unsaturated cement systems in isothermal conditions," Cement and Concrete Research, vol. 35, no. 1, pp. 141-153, 2005.

[25] Y. Chen, J. Gao, L. Tang, and X. Li, "Resistance of concrete against combined attack of chloride and sulfate under dryingwetting cycles," Construction and Building Materials, vol. 106, pp. 650-658, 2016.

[26] C. Fu, H. Ye, X. Jin, D. Yan, N. Jin, and Z. Peng, "Chloride penetration into concrete damaged by uniaxial tensile fatigue loading," Construction and Building Materials, vol. 125, pp. 714-723, 2016.

[27] Y. Wang, Y. Cao, P. Zhang et al., "Water absorption and chloride diffusivity of concrete under the coupling effect of uniaxial compressive load and freeze-thaw cycles," Construction and Building Materials, vol. 209, pp. 566-576, 2019.

[28] Z. Ma, T. Zhao, and X. Yao, "Influence of applied loads on the permeability behavior of ultra high performance concrete with steel fibers," Journal of Advanced Concrete Technology, vol. 14, no. 12, pp. 770-781, 2016.

[29] H. Wang, C. Lu, W. Jin, and Y. Bai, "Effect of external loads on chloride transport in concrete," Journal of Materials in Civil Engineering, vol. 23, no. 7, pp. 1043-1049, 2011.

[30] Z. Ma, G. Ba, and Z. Duan, "Effects of high temperature and cooling pattern on the chloride permeability of concrete,"
Advances in Civil Engineering, vol. 2019, Article ID 2465940, 13 pages, 2019.

[31] M. Zhang, P. G. Wang, and F. H. Wittmann, "Influence of moisture content on chloride diffusion in concrete," Restoration of Buildings and Monuments, vol. 20, no. 2, 2014.

[32] R. du Plooy, G. Villain, S. Palma Lopes, A. Ihamouten, $\mathrm{X}$. Dérobert, and B. Thauvin, "Electromagnetic non-destructive evaluation techniques for the monitoring of water and chloride ingress into concrete: a comparative study," Materials and Structures, vol. 48, no. 1-2, pp. 369-386, 2015.

[33] Z. Ma, F. Zhu, and T. Zhao, "Effects of surface modification of silane coupling agent on the properties of concrete with freeze-thaw damage," KSCE Journal of Civil Engineering, vol. 22, no. 2, pp. 657-669, 2018.

[34] Y. Tian, Z. Tian, N. Jin, X. Jin, and W. Yu, "A multiphase numerical simulation of chloride ions diffusion in concrete using electron microprobe analysis for characterizing properties of ITZ," Construction and Building Materials, vol. 178, pp. 432-444, 2018.

[35] Q. L. Zhao and Y. Z. Zhang, "Concentration distribution of chloride ion under the influence of the convection-diffusion coupling," Advances in Materials Science and Engineering, vol. 2017, Article ID 2076986, 10 pages, 2017.

[36] S. B. Xue, P. Zhang, J. W. Bao, L. F. He, Y. Hu, and S. D. Yang, "Comparison of mercury intrusion porosimetry and multiscale X-ray CT on characterizing the microstructure of heattreated cement mortar," Materials Characterization, vol. 160, Article ID 110085, 2020.

[37] T. Ding, J. Xiao, and A.-u.-R. Khan, "Behavior of concrete beam-column frame joints with DfD connections: a simulation study with interface modelling," Engineering Structures, vol. 189, pp. 347-358, 2019.

[38] Y. Zhang, S. Wang, B. Zhang et al., "A preliminary investigation of the properties of potassium magnesium phosphate cement-based grouts mixed with fly ash, water glass and bentonite," Construction and Building Materials, vol. 237, Article ID 117501, 2020.

[39] C. Wang, J. Xiao, C. Zhang, and X. Xiao, "Structural health monitoring and performance analysis of a 12-story recycled aggregate concrete structure," Engineering Structures, vol. 205, Article ID 110102, 2020.

[40] C. Wang, J. Xiao, C. Wang, and C. Zhang, "Nonlinear damping and nonlinear responses of recycled aggregate concrete frames under earthquake loading," Engineering Structures, vol. 201, Article ID 109575, 2019.

[41] S. I. Ahmad and M. S. Rahman, "Mechanical and durability properties of induction-furnace-slag-incorporated recycled aggregate concrete," Advances in Civil Engineering, vol. 2018, Article ID 3297342, 11 pages, 2018. 